\title{
Account of Practice: using action learning to develop and educate undergraduate management degree apprentices
}

\author{
Becky Quew Jones \& Cheryl Brook \\ University of Portsmouth
}

\begin{abstract}
This account of practice offers an example of the use of action learning within the undergraduate Degree Apprenticeship Curriculum of a UK university, specifically the Chartered Manager Degree Apprenticeship. This programme is aimed at an age diverse group who are supported by their employers through the levy to improve their knowledge, skills and behaviours in alignment to the standards required in becoming a Chartered Manager. We discuss the background and context of the course followed by an account of some aspects of the action learning process used to support and challenge apprentices as they worked on their projects. The account suggests that the application of knowledge to work based problems on the Degree Apprenticeship Programme was enhanced by the action learning process. We reflect on the challenges and opportunities presented by introducing action learning on this undergraduate programme, such as the value of the safe space created and the difficulties of getting to grips with reflection.
\end{abstract}

KEYWORDS: Action learning, degree apprenticeships; work-based learning; chartered manager standards.

\section{Background to Degree Apprenticeships and Work Based Learning}

This account of practice describes some aspects of the progress of the first action learning set used on the degree apprenticeship programme at the University of Portsmouth. The apprentices on this programme are undertaking an undergraduate degree, in this case a BA (Honours) in Business Leadership and Management as part of the Chartered Manager Degree Apprenticeship. Degree Apprenticeships were introduced in the UK in 2014 with the aim of increasing the number of apprenticeships to over three million by 2020 , and thereby offering some measure of equality of opportunity for those choosing to undertake an undergraduate programme via a non-traditional route (Mulkeen et al. 2017).

The aim of the Chartered Manager Degree Apprenticeship is to develop apprentices' knowledge, skills and behaviours against a set Chartered Manager standard. The standard was agreed by a group of UK employers and was accepted by the Education and Skills Funding Agency in 2015. According to the Chartered Management Institute (CMI) a Chartered Manager is someone who can take responsibility for people, projects, operations and/or services to deliver long term organisational success, with the professional recognition of their ability to deliver impact, behave ethically and demonstrate their commitment to continual learning and development. The programme is for people in roles where they have significant responsibilities and can benefit from applied and formal learning. The standard itself covers such areas as operational strategy, project management, leading and 
managing people and business finance, but also less easily assessed skills and competences such as self-management and awareness of self and others (ie the ability to understand impact on others). This awareness of self and others element also encompasses 'knowing how to be self-aware and recognise different learning styles; knowing how to use emotional and social intelligence, and active listening and open questioning to work effectively with others' (Chartered Manager Standard). Management and business education is offered by the provider (the University) but learning from practice in the workplace is a key underpinning strategy for the programme as a whole (Raelin, 2008).

Work based learning is a central feature of the degree programme. We have observed that the apprentices often demonstrate greater engagement when undertaking work based learning projects; there is a sense of authentic learning when they can make a real difference in the workplace and in terms of their own practice. Employers benefit in a number of ways; they can 'grow their own staff', they can directly benefit from government funding, and because they have direct links with the university the learning can be more tailored to organisational needs. Revans of course, railed against the gap between the 'book' and the 'tool' culture viewing it as potentially leading to a more fractured society. He argued for a closer engagement between academy and industry (the world of work) as a necessary corrective action. Through the degree apprenticeship programme this gap has more chance of being bridged, though it requires the active engagement of all the stakeholders for this to come about. Nonetheless in this programme the idea of students not only becoming learners at work but learners through work is given prominence.

However, there are still challenges across the programme for the learner to transfer what is gained in the academic environment back into the workplace and to meet the requirement to practise new skills and behaviours. This 'dual identity' as worker and learner can become confusing for the apprentice particularly if left unsupported by their stakeholders, tutors and supervisors and their line managers back in the workplace. For degree apprenticeship programmes to succeed the work- based projects and problems that the apprentice elects to work on must add value for the organisation. It is vital that there is meaningful collaboration with employers throughout the life of the course, and especially concerning the work based features of the programme.

The apprentices who study at the University of Portsmouth on the Chartered Manager Degree Apprenticeship are diverse in age, previous academic experience, management roles and local organisations. Some have not undertaken any kind of formal study for some time. They are 'earning whilst they are learning' which results in an extremely busy work and study schedule which must be effectively managed for them to succeed. The students spend approximately one day a week at the University.

In 2016 the first author was appointed Programme Director for degree apprentices and during the design stage of the course helped to ensure that there were opportunities for the apprentice to be assessed on their ability to solve work-based challenges directly through various work-based modules. The apprentices are 
encouraged to resolve the challenges to ensure a positive impact back into their own workplace, with additional guidance given to their line managers as levy payers. In the final year they are required to both identify and work on a significant work based problem / project and this is the aim of their final year Work Based Learning Project (WBL). Due to the nature of the apprenticeship there is not only the requirement for the apprentice to pass the module based assessment but also to meet the requirements of the End Point Assessment (EPA) encompassing a work based learning project together with evidence of learning and continuous professional development documented in an ePortfolio.

As we have said, to meet the requirements of the apprenticeship we are also required to be mindful of the Chartered Manager Standards. There is an expectation that the apprentices undertake continuous professional development during the required $20 \%$ of time 'off the job' (BIS, 2015) which includes both the University study days but also learning opportunities in the workplace. For the work based learning projects the required skills and behaviours have been mapped against the standards. For example, there is an explicit requirement to 'use active listening and open questioning to structure conversations and discussions, and be able to challenge when appropriate' and 'enable others to achieve by developing and supporting them through coaching and mentoring.' The action learning sets provide opportunities to develop and practise some of these 'hard to teach' management skills.

The university has a history of work based learning. Brook and Corbridge (2015) offered an analysis of how this had been developed within undergraduate programmes previously where students used industry placements as a source of project work. Many of the practices still apply (such as having an agreed learning contract between employer, student and university) however the application of action learning on this new undergraduate degree is an innovation. Work based learning projects have to be substantial pieces of work for a 40-credit unit. Brook and Corbridge (2015) offered examples such as the development and management of an organisational engagement survey, producing a report on internal communications (which was to go before the company board) and organising an employee wellbeing event including a charity walk, sponsored stalls, themed refreshments and a building 'light show'.

In the traditional work-based learning approach adopted by the university there are three parts to the assessment process: a learning contract which identifies the kind of output to be produced for the organisation and the milestones along the way to achieving it. Secondly the 'artefact' itself, together with an outline of how it was produced, and finally an academic commentary, which brings together academic and theoretical explanations and the practicalities of producing the specific artefact for the organisation in question. The degree apprentices programme follows this pattern, but there is much more emphasis on reflective practice and of course there is the introduction and use of action learning as a new core feature.

\section{Introducing Action Learning}

Action learning is taken to be a way of considering and potentially solving workbased problems using iterative rounds of questioning, action, reflection and learning 
with a small set of peers (Brook, Pedler \& Burgoyne, 2012). Whilst action learning has found its place on post-graduate programmes it is less common to find it on undergraduate programmes. However, given the type of students we were dealing with we had few doubts it would work. We believed the approach would offer degree apprentices the opportunity to be more collaborative, to test out their ideas and more importantly develop their practice using their work projects, and, moreover, it would give them opportunities to challenge and support each other in a safe environment.

The primary expectation of action learning and introducing the action learning sets was to provide the apprentices with a learning experience that was deeper and richer when working on their real-time problems occurring in their own work setting. We felt that action learning would offer an environment that would encourage group reflection which is well documented as a successful way of reflecting. The 'reflective discourse' with their peer group would offer insights into their workplace challenges and an opportunity for set members to make sense of their own actions and issues (Raelin, 2008). We anticipated that questioning from peers would encourage the development of wider perspectives leading to their greater sense-making around the changes they felt that they needed to make to reach project objectives. Questioning played a very significant part in set meetings because we (and they) did not want the set to turn into a simplistic exchange of advice.

\section{The degree apprentices' action learning set}

We began the process with an induction programme in which we talked with the apprentices about work-based learning and introduced them to the idea of action learning through a range of short inputs and group exercises. The first set of seven degree apprentices met thereafter on a weekly basis to work as part of an action set to work on their projects / problems. The students worked for very different organisations including a call centre, and interior fit out company, two university departments and a management consultancy. None of the apprentices had previously encountered the action learning approach.

The apprentices were required to agree a project idea with their line manager(s) back in their respective organisations and complete a learning contract. The learning contract in this context is an agreement between organisation, university and apprentice. The term 'learning contract' is used in the sense of an 'understanding' rather than a binding 'legal-like' agreement. It includes the following key features:

- A clear outline of what the student will deliver for the organisation- the output of artefact (for example, a training programme, a marketing plan, a work based-event, an induction programme etc)

- An identification of the knowledge and skills required to undertake the project, and the gaps in that skills and knowledge base, and an indication of the resources (and support) needed to develop the project.

- An idea of the learning and skills they need to complete the project and how they intend to meet these needs;

- An identification of the evidence that will be supplied to help evaluate the learning and quality the artefact, and how this will be validated. 
To offer an example, one of the projects involved the design and trialling of new type of networking event. Networking was seen as especially important to the set member's organisation, was indeed one of its core purposes and there were a number of issues around the need to encourage the development of more diverse networks. The set member's specific output was a report and a presentation on how this was to be achieved in practice.

In the learning contract a clear description of the evidence to be supplied is needed to help assess learning and validate the project. In the example given above, the evidence included statements from colleagues, including his line manager, a youtube video of his presentation to his organisation on his project work, email trails and minutes of meetings.

One of the main elements to be produced by the apprentices as part of their project/artefact submission was a written reflective account of their work-based learning journey. The action learning set offered the apprentices the opportunity to discuss problems they encountered along the way with their project, and to reflect on what they had learned in progressing (or perhaps failing to progress) their work. This helped to give some shape to those reflective accounts. After each set meeting, the apprentices wrote a brief personal reflective account based on Pedler \& Abbott's (2013) template answering questions such as:

- Key things I learned about the project/problem today

- Action steps following today's meeting

- Key things I learned about others' projects

This approach focused students' minds on the reflection work that they needed to do: what they experienced, what they had learned from what they had experienced and what they intended to do differently in the future. The apprentices agreed that they wanted to collect the questions posed to them at each set meeting (on post its) and take them away to reflect upon them later on. A snapshot of a set of questions posed by the set to one student at one set meeting is given below.

The apprentices had few difficulties in opening up about some of the issues which were preventing progress or indeed enabling it in relation to their projects. We had spent some time at the beginning of the process talking about ground-rules for the operation of the set, and the idea of a 'safe space' in which to share issues and what that might look like in practice. The ground-rules, of course, were identified by the set members themselves.

Although no two set meetings were alike, the approach we took tended to be as follows:

- Brief 'letting off steam' about any current pressing work issues, and a brief review of ground-rules;

- Agenda setting - the set determines how the meeting will work and allocates time accordingly;

- Presenting their issue, giving an account of where they were up to with the project and what questions or problems were uppermost in their mind. Usually 
the presenting set member would then ask the set for help with a specific problem or aspect of their project work;

- Iterative rounds of questioning, challenging, supporting and offering resources all the while keeping the focus on the problem/issue holder;

- Reflective review and discussion, and the problem/issue holder maps out the next steps.

We wanted to encourage the development of a 'safe space' for set members to discuss conflicts, anxieties and failures as well as positive developments and actions. Set meetings were always held at the university, and in a room in which people could directly face each other, in other words not in a typical classroom setting.

Questioning was central to the way in which the sets operated. To this end set members found Pedler and Abbott's (2013, 77-8) 'thinking, feeling, willing' categories of questions useful. The feeling questions were especially helpful in focusing attention on the emotions and anxieties set members were experiencing in relation to particular events and discussions in the workplace and in set meetings.

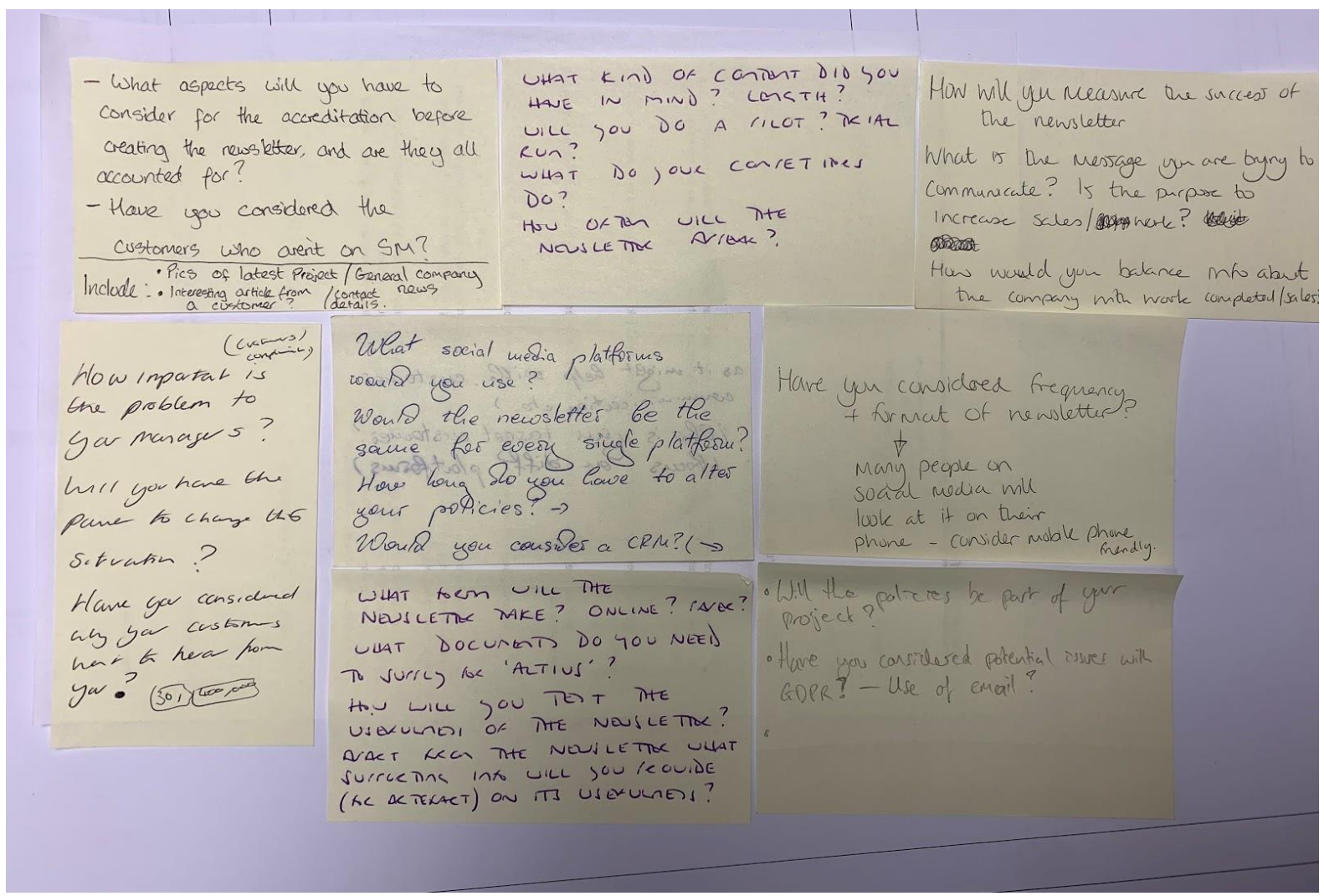

(Post-it questions by kind permission of Matt Barnes)

Spending a significant amount of the set meeting asking questions was one of the elements of the action learning process which the apprentices took to very easily. This might be explained by the fact that they are already immersed in a work environment and all of them had significant work experience to draw upon. Some apparently straightforward questions about the project (in the case above concerned with communicating and keeping in touch with key customers) often generated the 
most debate, such as one highlighted above: what is the key message you are trying to communicate? What is its purpose?

One of the apprentices noted how when he got stuck for ideas as to how to recruit volunteers for a communication forum he was helped by the various ideas which emerged from the set meeting. These included targeting staff whom he knew and with whom he already have a good relationship; offering to keep people informed of progress, and finally, offering a small incentive or 'thank you' for taking part.

Once introduced to the idea of taking time to question, they produced a significant volume of questions for the presenting set member at every meeting. They also had no difficulty in asking the specific help when they need it. For example, one of the apprentices had to produce a key paper on their project and made use of one of the set meetings to test out ideas for the content of the paper he was about to submit to his executive board.

\section{Outcomes of the process of action learning}

The benefits of the action learning process were not fully realised until the work was submitted and the apprentices were working towards their End Point Assessment. The End Point Assessment (EPA) which is a CMI requirement, takes place after the degree is awarded and offers a further opportunity for some of the outcomes of both WBL and action learning to become more apparent. At the start of the academic year the students made use of an e-portfolio to chart their achievements which is also drawn upon by students in the EPA. The EPA is not attended by academic staff; only the student's line manager and CMI appointed external assessor are in attendance with the presenting student. At the EPA the students present a summary of their work and achievements. Some of the benefits of the action learning approach which emerged have included:

- development of the apprentices questioning style - using both social and emotional intelligence and asking thoughtful and insightful questions;

- a greater degree of inclusivity and involvement for all members of the set - no member was isolated, something which had been noted in other group work sessions;

- $\quad$ enhanced active listening and more challenging of each other in group work;

- peer mentoring skills enhanced by the apprentices becoming involved with each other's projects and being keen to offer questions, ideas and support

- raised level of emotional engagement with their WBL projects - joy at progress and shared frustration and even anger at non progression;

- greater accountability for the apprentices as they attempted to complete and feedback on their weekly actions.

From an academic point of view it has of course been pleasing to see apprentices do well and in some cases gain firsts as a result of their engagement with and commitment to the work based learning programme. But a more striking observation is that the apprentices gained in confidence and through the operation of the action learning set could demonstrate some of those 'harder to assess' competences required of the chartered manager. 


\section{Insights}

The action of putting this account of practice together has been another useful opportunity for us to reflect on how the innovation of using action leaning on this programme has worked in practice, and to reflect on what we might need to do differently as we go into a new academic year. A problem for us was that the way in which the sets were originally timetabled did not allow as much time as we would have liked to deal with reflective work. This is something we have worked to change for the next academic year. Given the pressures we experienced with timetabling we found we needed to work quickly as facilitators at ensuring the apprentices got used to the idea of questioning and challenging each other very early on in the life of the programme. They needed to grasp the idea of being self-directed learners from the outset.

When some of the apprentices encountered problems (in some cases very challenging problems such as projects being 'pulled' or radically changed) it was sometimes hard for them to see that there was a good deal of learning and actionable knowledge still to be had out of it - especially learning from things that had gone wrong. When we carry out induction in the new academic year this is one of the things we want to emphasise and that such challenges (although difficult for the student) do not necessarily mean the automatic failure of their work-based learning project. On the contrary, such experiences can lead to very rich learning.

\section{Conclusion}

Action learning is a very suitable vehicle for apprentices given their experience and their rootedness in the work environment. Where there are challenges in implementing projects these can provide a useful focus for learning and reflection in set meetings. In terms of developing programme for the future we will need to develop more action learning facilitators as the programme expands. We also acknowledge that we need to spend more time helping students to develop the skills to write reflectively as this is now a key component of the assessment process. Some of the students struggled with reflection, and even more so in getting their reflections onto paper. This is why we placed an emphasis on encouraging students to write a short reflective account after each meeting. It is also why the apprentices liked to write questions down for the problem presenter so that they could take them away afterwards to think about them. We have built more time into the programme for the next academic year to develop these aspects. We are also now in a position to invite past apprentices back to talk about their action learning and work-based learning experiences.

The authors would like to thank and acknowledge the contribution of the first UoP degree apprentices' action learning set in producing this account of practice with special thanks to Tom Colbeck, Matt Barnes and Chris Bayliss. 
Word count: 3905

\section{References}

Brook, C., Pedler, M., \& Burgoyne, J. 2012. Some debates and challenges in the literature on action learning: the state of the art since Revans. Human Resource Development International, 15(3), 269-282

Brook, C., \& Corbridge, M. 2016. Work-based learning in a business school context: artefacts, contracts, learning and challenges. Higher Education Skills and Work Based Learning, 6(3), 249-260

Chartered Management Institute Website (CMI) at :

https://www.managers.org.uk/apprenticeships-and-epa/employers

Mulkeen,J., Abdou A., Leigh J, \& Ward P. 2017. Degree and higher apprenticeships an empirical investigation of stakeholder perceptions of challenges and opportunities. Studies in Higher Education 44:2, 333-346.

Pedler M. \& Abbott, C. 2013. Facilitating learning: A Practitioner's Guide. Maidenhead Open University Press.

Revans, R. 1980. Action learning. New Techniques for Management. London: Blond and Briggs; 1980.

Raelin, J. 2008. Work Based Learning San Francisco: Jossey-Bass.

\section{Notes on contributors:}

Becky Quew Jones is Director of Degree Apprenticeship programmes at the University of Portsmouth.

Cheryl Brook is a senior lecturer in HRM/D at the University of Portsmouth. 